\title{
A KDR-binding peptide (ST100,059) can block angiogenesis, melanoma tumor growth and metastasis in vitro and in vivo
}

\author{
LUCA RASTELLI $^{1,4}$, MARIA LUISA VALENTINO ${ }^{2}$, MELISSA CORSO MINDERMAN ${ }^{1,5}$, JUDITH LANDIN ${ }^{1,6}$, \\ URIEL M. MALYANKAR ${ }^{1,7}$, MARY K. LESCOE ${ }^{1,8}$, RICHARD KITSON $^{1}$, KENNETH BRUNSON $^{1}$, LINA SOUAN ${ }^{1,9}$, \\ SALVATORE FORENZA ${ }^{1,3}$, RONALD H. GOLDFARB ${ }^{1,3}$ and SHAFAAT A. RABBANI ${ }^{2}$ \\ ${ }^{1}$ Sopherion Therapeutics Inc., New Haven, CT, USA; ${ }^{2}$ Department of Medicine and Oncology, \\ McGill University Health Center, Montreal, QC, Canada
}

Received December 20, 2010; Accepted February 10, 2011

DOI: $10.3892 /$ ijo.2011.1040

\begin{abstract}
A major goal of treatment strategies for cancer is the development of agents which can block primary tumor growth and development as well as the progression of tumor metastasis without any treatment associated side effects. Using mini peptide display (MPD) technology, we generated peptides that can bind to the human vascular endothelial growth factor (VEGF) receptor KDR. These peptides were evaluated for their ability to block angiogenesis, tumor growth and metastasis in vitro and in vivo. A D-amino acid peptide with high serum stability $(\mathrm{ST} 100,059)$ was found to have the most potent activity in vitro as indicated by inhibition of VEGF stimulation of endothelial cells. It was also found to be the most active of the series in blocking VEGF-mediated activity in vivo, as measured in Matrigel-filled angioreactors implanted in mice. ST100,059 blocks VEGF-induced MAPK phosphorylation, as well as inhibits VEGF-induced changes in gene expression in HUVEC cells. In in vivo studies, treatment of female C57BL/6 mice inoculated with B16 mouse melanoma cells with ST100,059 resulted in a dose-dependent decrease in tumor volume and lung metastasis as compared to control groups of animals receiving vehicle alone. These studies demonstrate that by using MPD, peptides can be identified with enhanced affinity relative to those discovered using phage
\end{abstract}

Correspondence to: Dr Ronald H. Goldfarb, Sopherion Therapeutics LLC, 104 Carnegie Center, Princeton, NJ 08540, USA

E-mail: rgoldfarb@sopherion.com

Dr Shafaat A. Rabbani, McGill University Health Centre, 687 Pine Avenue West, Room H4-67, Montreal, Quebec H3A 1A1, Canada

E-mail: shafaat.rabbani@mcgill.ca

Present addresses: ${ }^{3}$ Sopherion Therapeutics LLC, Princeton, NJ 08540, USA; ${ }^{4}$ EMD Serono Research Institute, Rockland, MA 02370 , USA; ${ }^{5} 454$ Life Sciences, A Roche Company, Branford, CT 06405 , USA; ${ }^{6}$ Thompson CT School System, USA; ${ }^{7}$ MannKind Corporation, Valencia, CA 91355, USA; ${ }^{8}$ Pfizer, Inc., Groton, CT 06340, USA; ${ }^{9}$ King Hussein Cancer Center, Amman 11941, Jordan

Key words: angiogenesis, KDR, peptide, melanoma, tumor metastasis display. Based on these studies we have identified one such peptide ST100,059 which can effectively block tumor growth and metastasis due to its anti-angiogenic effects and ability to block intracellular signaling pathways involved in tumor progression.

\section{Introduction}

Angiogenesis is essential for the growth of solid tumors and for tumor metastasis. The generation of new capillaries involves a multi-step process, which includes dissolution of the basement membrane of the originating vessel, endothelial cell migration and proliferation, and formation of a new vascular tube (1-3). The evidence currently favors a model where tumor cells under harsh conditions of their microenvironment, such as hypoxia, are triggered to express and secrete several proangiogenic factors, such as VEGF and platelet-derived growth factor (PDGF). These growth factors play important but distinct roles in the multi-step process of angiogenesis (4). Suppression of any one of these steps can inhibit the formation of new vessels and therefore affect tumor growth and generation of metastases. Moreover, unlike tumor cells, endothelial cells are thought to be genetically stable and therefore not likely to mutate into drug-resistant variants with the caveat that recent work has shown that tumor derived cells make up part of the lining of blood vessels in the tumor and that potentially tumor associated endothelial cells might be genetically instable $(5,6)$. Since they line the inside of blood vessels, endothelial cells are easily accessible to circulating drugs. Hence, anti-angiogenic therapies which target endothelial cells are providing a promising mechanism for cancer treatment.

Among the members of the VEGF family (VEGF-A, B, C, and D) and their receptors (VEGF receptor-1 or Flt-1, VEGF receptor-2 or Flk-1/KDR, VEGF receptor-3 or Flt-4), the interaction between VEGF-A and KDR is believed to be the most important for angiogenesis during tumor formation because most of the VEGF related angiogenic properties (mitogenicity, chemotaxis and induction of morphological changes) are mediated by interaction with KDR (7). Several approaches have been used to target this interaction. Most common is the use of ATP mimetics that are selective for the inhibition of the tyrosine kinase activity of Flk-1 and are currently under clinical 
development (8). Another approach is targeting angiogenesis by treatment with antibodies against either VEGF or its receptors $(9,10)$.

Development of small peptides which can demonstrate good potency and safety profiles, and have a reasonably low cost of manufacture will be of significance for their development as therapeutic agents. Moreover, our technology platform can rapidly generate novel peptides for specific biological targets. Small peptides generated by phage display that block binding of VEGF to KDR have previously been described. One of these peptides was shown to inhibit VEGF-induced angiogenesis in a rabbit corneal model (11). However, this peptide had a rather high $\mathrm{IC}_{50}$ of $200 \mu \mathrm{M}$, suggesting that improvement could be gained by applying more advanced display technologies.

We therefore applied our MPD technology to identify new KDR binding peptides with improved characteristics. MPD circumvents some problems inherent with phage display. MPD's minicells have several advantages, including independent cell surface expression of large non-constrained peptides.

In this study, a random peptide library was displayed using the MPD technology and screened to identify peptides blocking the binding of VEGF to KDR by isolating peptides that bound to recombinant human KDR. One of the KDR binding peptides, ST100,038, although similar in sequence to peptides previously identified by Binetruy-Tournaire et al using phage display, had a significantly lower $\mathrm{IC}_{50}$ of $40 \mu \mathrm{M}$ vs. $200 \mu \mathrm{M}$, as determined by the inhibition of endothelial cell proliferation (11). In vivo analysis using the angioreactor Matrigel plug assay confirmed the ability of ST100,038 to inhibit VEGF-induced angiogenesis when added to the plugs. Moreover, a serum-stable all D-amino acid inverted sequence version, ST100,059, inhibited tumor progression, angiogenesis and lung metastasis in a B16 mouse melanoma model. These results demonstrate the ability of MPD to identify peptides with enhanced affinity relative to those discovered using phage display. In addition, ST100,059 may be useful to develop as a novel anti-angiogenic agent for cancer treatment.

\section{Materials and methods}

Library construction and screening. The pBS17K plasmid allows the controlled expression of oligonucleotide libraries genetically fused to a fragment of $17 \mathrm{~K}$ antigen of Rickettsia rickettsii. To generate $\mathrm{pBS} 17 \mathrm{~K}$, an $\mathrm{N}$-terminal fragment of the $17 \mathrm{~K}$ antigen of $R$. rickettsi, containing the lipid modification site, was assembled by annealing DNA oligos and cloned into the Xba-Bam HI sites of $\mathrm{pBS}$. To generate the library of random peptides, random oligos with the general sequence BamHI99mer-EcoRI, where BamHI and EcoRI represent two 15 bp long fixed sequences containing the corresponding restriction enzyme recognition sites, were synthesized and then PCR amplified using primers corresponding to the fixed termini. The products were digested with the appropriate restriction enzymes and then cloned into plasmid pBS17K digested with BamHI-EcoRI.

Costar high binding plates (3361) were coated with $5 \mu \mathrm{g} / \mathrm{ml}$ KDR receptor (R\&D Systems, Minneapolis, MN) diluted in coating buffer and then rinsed with phosphate-buffered saline (PBS). An aliquot of the Minicell random library was diluted
1:1 with washing buffer prepared at $2 \mathrm{X}$ concentration (i.e., $\mathrm{PBS}$, PBS with $500 \mathrm{mM} \mathrm{NaCl}$, PBS with $1 \mathrm{M} \mathrm{NaCl}$, PBS plus $0.2 \%$ NP-40, PBS plus $0.02 \%$ SDS) with $0.1 \%$ BSA and $25 \mu \mathrm{g} / \mathrm{ml}$ kanamycin and added at $50 \mu \mathrm{l} /$ well. Plates were incubated at $4^{\circ} \mathrm{C}$ overnight. Minicells were removed, plates were washed three times for $1 \mathrm{~min}$ with $200 \mu \mathrm{l}$ of appropriate buffer followed by $50 \mu \mathrm{l} \mathrm{PBS} /$ well for $3 \mathrm{~h}$ at $4^{\circ} \mathrm{C}$. The number of bound minicells was determined as colony number (by 'rescuing' the corresponding plasmid DNA and transforming competent E. coli DH5alpha cells).

Peptide synthesis. Peptides were synthesized using Fmoc chemistry and purified using Applied Biosystems 433A peptide synthesizer (Foster City, CA) and Waters Autopurification system with a ZQ mass spectrometer as the primary detector (Milford, MA).

KDR binding assay to synthetic peptide. A modified ELISA was used where wells of a high binding 96-well plate (Corning Costar 3361) were coated overnight with the test peptide(s) or $100 \mathrm{ng}$ of VEGF as positive control, followed by the addition of $5 \mu \mathrm{g} / \mathrm{ml}$ recombinant human KDR (R\&D Systems 357-KD). After washing with PBS $+0.05 \%$ Tween-20, $100 \mathrm{ng} / \mathrm{ml}$ antibiotin-KDR goat polyclonal antibody (R\&D Systems BAF357) were added followed by a 1:1000 dilution of ExtrAvidinperoxidase (Sigma, St. Louis, MO). The signal was developed with TMB peroxidase substrate (Sigma) and recorded at $370 \mathrm{~nm}$ using Bio-Tek PowerWave XS equipment.

Endothelial cell assays. Bovine retinal endothelial (BRE) (VEC Technologies, Inc., Rensselaer, NY) cells were maintained in EGM-2 media (Cambrex Bioscience, Baltimore, MA). Human umbilical cord endothelial (HUVEC) cells were maintained in M200 media (Cascade Biologics Inc., Portland, OR). Two types of cell assays were carried out as follows: on day one cells were starved for either $6 \mathrm{~h}$ or overnight, then trypsinized and plated in 96-well plates in $100 \mu \mathrm{l}$ of Optimem (Invitrogen, San Diego, CA) plus $1 \%$ fetal bovine serum (FBS). One hundred $\mu \mathrm{l}$ of Optimem plus $1 \%$ FBS were added to the wells containing, where appropriate, VEGF to a final concentration of $25 \mathrm{ng} / \mathrm{ml}$, and the various peptides. Otherwise BRE cells were preplated in 96-well plates in complete media on day one, and starved during the next day. VEGF and peptides where then added, where appropriate, as above. With both assays, after 72-h incubation, the amount of live cells in each well was measured with the WST-1 assay (Roche, Indianapolis, IN).

For measuring the effect of peptides on VEGF-induced intracellular signaling, HUVEC cells were treated initially as above. After starvation, the media were replaced with starvation media \pm peptides and cells were incubated for $2 \mathrm{~h}$. Media were then replaced with serum-free media containing $25 \mathrm{ng} / \mathrm{ml}$ of human VEGF165 and incubated for $10 \mathrm{~min}$. Cells were then washed with $2 \mathrm{mM}$ sodium orthovanadate in PBS, harvested in NP40 lysis buffer with sodium orthovanadate and PMSF and then analyzed by Western blot analysis.

For gene expression analysis, at the end of the treatment, total cellular RNA was prepared using Trizol (Invitrogen) as described by the manufacturer. Total RNA $(10 \mu \mathrm{g})$ was then hybridized on Affymetrix Human U133 Plus 2.0 arrays (Expression Analysis, Durham, NC) as described by the 
manufacturer. The resulting data were processed using the Affymetrix GCOS software.

Stability studies of peptides in 10\% serum. Peptide were diluted to $100 \mu \mathrm{M}$ in OptiMem media plus $100 \mu \mathrm{l} / \mathrm{ml}$ penicillin, $100 \mu \mathrm{g} / \mathrm{ml}$ streptomycin sulfate plus $10 \% \mathrm{FBS}$. The diluted samples were placed in a 24-well tissue culture plate in an incubator at $37^{\circ} \mathrm{C}$. Aliquots of 50-100 $\mu \mathrm{l}$ were removed at various times. For analysis by LC/MS, samples of $20 \mu 1$ were separated on a $\mathrm{C} 18$ column $(4.8 \times 250 \mathrm{~mm})$ with a gradient of acetonitrile/ water $0.1 \%$ TFA and analyzed using a single quad mass spectrometer. Singly or multiply charged peaks were detected depending on the mass of the peptide. Peptide degradation was determined in two ways: loss of peak area in the chromatogram produced using the mass spectrometer as the detector and loss of the main peak in the mass spectrum with simultaneous appearance of a peak(s) from a breakdown product.

Animal protocols. The Matrigel angiogenesis assay was performed as described previously (12). For in vivo studies B16-F1 melanoma cells were grown to subconfluence and single cell suspensions with greater than $90 \%$ viability were briefly kept in ice until use for injection into recipient mice $(13,14)$. Female C57BL/6 mice with a mean body weight of $20 \pm 2$ g were purchased from Charles River Inc., St. Constant, Quebec, Canada. Eight to ten-week-old mice were used in accordance with institutional review board (IRB) guidelines. For subcutaneous (s.c.) implantation, each mouse was injected with $5 \times 10^{5}$ cells in $200 \mu \mathrm{l}$ of saline. For i.v. injection, mice received $1 \times 10^{5}$ cells in $100 \mu \mathrm{l}$ of saline. Peptides (formulated in water) were administered i.p. daily starting the day after tumor cell implantation. Doxorubicin was diluted in saline for injection. Groups of mice injected with tumor cells via s.c. route were randomly assigned to receive one of the following five treatment regimens ( $\mathrm{n}=10$ mice each) beginning one day after tumor cell implantation: a) daily intraperitoneal (i.p.) administration of vehicle (sterile water) as the negative control group; daily i.p. administration of ST100,059 at b) $20 \mathrm{mg} / \mathrm{kg}$, c) $40 \mathrm{mg} / \mathrm{kg}$ or d) $100 \mathrm{mg} / \mathrm{kg}$. Daily treatment was continued for 17 days (13). One dose of doxorubicin at e) $5 \mathrm{mg} / \mathrm{kg}$ was administered via intravenous (i.v.) route on day three after tumor cell implantation. Tumors became palpable around 9 days after injection of cells (14). Each tumor was measured with a caliper in two dimensions and the measurements converted to a number for tumor mass. The formula used was for an approximate prolate ellipsoid, $\mathrm{a} \times \mathrm{b}^{2} / 2$, where ' $\mathrm{a}$ ' is the longer tumor dimension and ' $b$ ' is the shorter dimension, and assuming unit density as $1 \mathrm{~mm}^{3}=1 \mathrm{mg}$. Tumor measurements were recorded every second day. Body weights were also recorded twice weekly. Tumor growth inhibition was assessed by the delay of tumor growth of the treated groups in comparison to the control group treated with vehicle only.

In lung metastasis studies, treatment was initiated the day after tumor cell injection. Following i.v. injection of $100 \mu \mathrm{l}$ of $1 \times 10^{5}$ B16-F1 cells, animal were randomized in to different groups ( $n=8$ mice per group) to receive one of the following three treatment regimens beginning one day after tumor cell injection: a) daily intraperitoneal (i.p.) administration of vehicle (saline) for 14 days as the negative control group; b) daily i.p. administration of ST100,059 at $100 \mathrm{mg} / \mathrm{kg}$ for 14 days or c) $100 \mathrm{mg} / \mathrm{kg}$ every other day for 14 days. Animals were sacrificed on day 15, and lungs harvested and fixed. Metastatic melanoma nodules were counted on the surfaces of all lung lobes and the number recorded as the number of lung metastases for each tumor-bearing animal.

Western blot analysis. For Western blot analysis we used Invitrogen Nupage system according to manufacturer's instructions. Briefly, tumor cells and tissues were dissolved in sample buffer, run on Nupage gels, blotted on PVDF membranes, incubated with the various antibodies following manufacturer's instructions.

\section{Results}

Library construction and screening. MPD is a new peptide display system that allows the inducible expression of oligonucleotide libraries genetically fused to part of the $17 \mathrm{~K}$ antigen of $R$. rickettsii which is displayed to the outer membrane. In addition, these libraries are introduced in mutants of Escherichia coli that undergo asynchronous cellular division producing minicells. Minicells contain plasmids and all the machinery for protein expression, but no bacterial chromosome. The expression of plasmid-encoded proteins is thus not compromised by bacterial gene expression. In addition, the peptides to be displayed being fused to the $17 \mathrm{~K}$ antigen of $R$. rickettsii are presented in a non-constrained conformation. After isolation via differential centrifugation, the purified minicells are the 'live beads' that are used to perform the actual peptide display screen.

A MPD library ( $3 \times 10^{5}$ clones) expressing random peptides with size up to 33 amino acids was screened to identify novel human VEGF receptor KDR binding peptides. Only 6 clones were deemed to be 'positive' in this screen. We focused our analysis on one of these six clones, $\mathrm{K} 3$, not only because the minicells expressing it bound specifically to recombinant KDR as opposed to recombinant KIT receptor (Fig. 1A) but also because its sequence is similar to KDR binding peptides previously identified using phage display.

Fig. 1B shows a homology alignment generated using Vector NTI which compares the sequences between the K3 peptide identified using MPD technology and the peptides EmboK4, EmboK5, EmboV4 and 1A11 $(11,16)$. This alignment reveals the existence of a consensus sequence, LPPHSS, which is highly conserved among all peptides. While BinetruyTournaire et al discussed the relevance of the LPP sequence for biological activity and mentioned the presence of the HSS sequence in two of the isolated peptides, the combination of both of them together in a single peptide is a novel finding specific to our work presented here (11).

As with the peptides identified in Binetruy-Tournaire et al alignment of the 038 sequence with VEGF did not produce any significant homology, suggesting that the peptide mimicked a discontinuous binding site (11).

In addition the alignment reveals two further regions of homology. The region ATS that is present in peptide 1A11 is partially conserved in the EmboV1 peptide (16). The $S$ residue is present in EmboK4. Moreover, another region of homology QSP is present in the peptide 1A11 and our peptide K3. Finally, the serine is conserved in the peptide EmboK3. We 
A

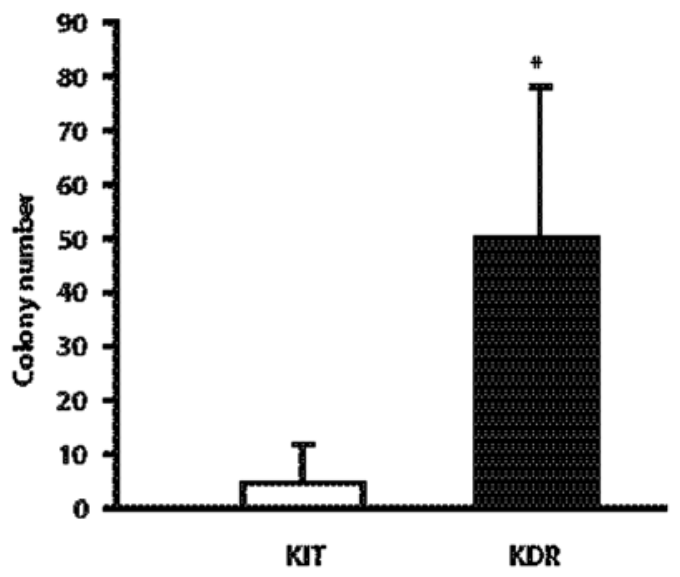

B

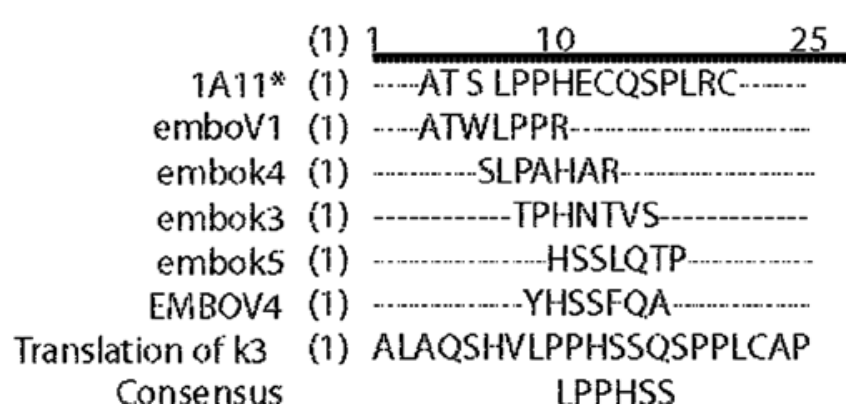

C

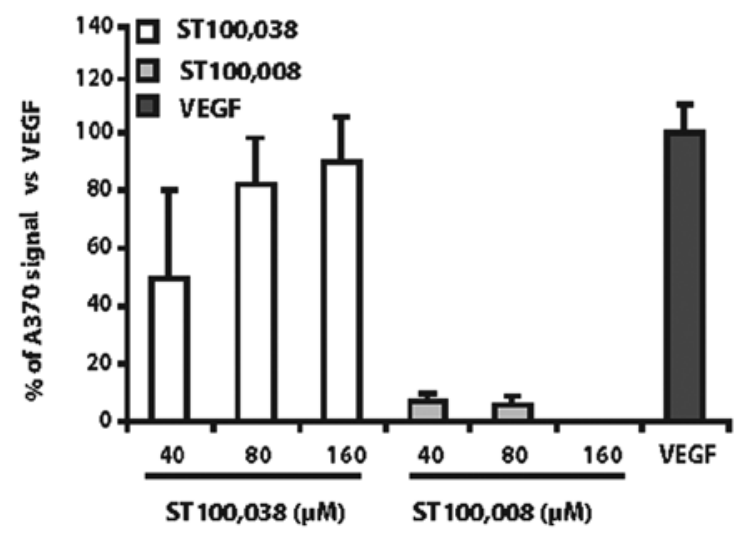

D

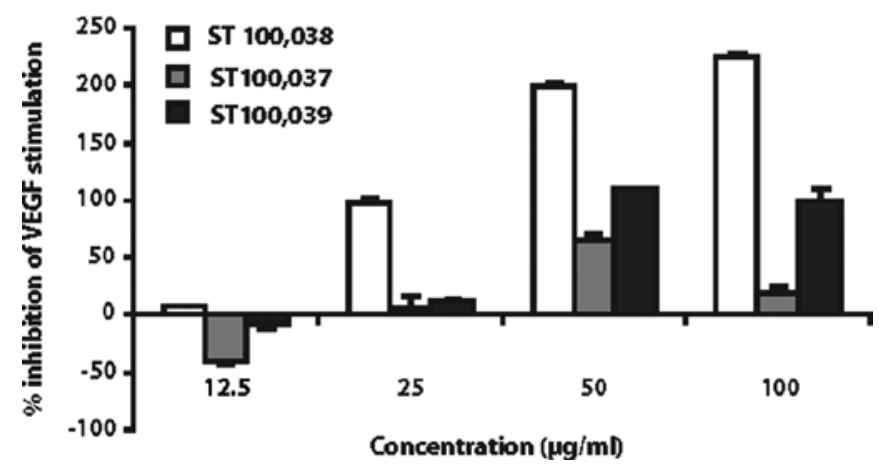

Figure 1. Identification and characterization of KDR binding minicells. (A), KDR binding minicells were identified using Sopherion MPD technology as described in Materials and methods. (B), Alignment of the sequence encoded by the KDR binding minicell with previously identified KDR binding peptides. (C), Recombinant human KDR was tested for binding to ST100,038 peptide and the control (CTL) peptide ST100,008 and compared with the binding obtained coating the wells with $100 \mathrm{ng} / \mathrm{ml}$ VEGF. (D), Effect of synthetic peptides ST100,038 and ST100,008 on the proliferation of bovine endothelial cells induced by VEGF in a dose-dependent manner. BRE cell cultures were grown in the presence of VEGF and were supplemented daily with various concentrations of peptides. Cells were measured WST1 after 5 days. Results are the mean \pm SEM of two separate experiments. Significant difference from control is shown by asterisks $(\mathrm{P}<0.05)$

decided therefore to synthesize the following peptides, LPPHSS, ATSLPPHSSQSP and LPPHSSQSP to test whether they bind to KDR.

KDR binding and inhibition of VEGF-mediated survivall proliferation. Recombinant human KDR was shown to bind to the synthetic peptide ST100,038 coated on a 96-well plate in a statistically significant and dose-dependent fashion (Fig. 1C). No binding of KDR to an unrelated peptide, ST100,008 assayed in parallel, was detected. The level of binding to wells coated with 100 ng VEGF was used as controls in this experiment.

The anti-angiogenic activity of the peptides was tested by measuring the level of inhibition of VEGF mediated survival/ proliferation of BRE cells. As shown in Fig. 1D the highest two concentrations of ST100,038 caused inhibition. Among the peptides, ST100,038 appeared to be the most active peptide in the assay. Concentrations above $25 \mu \mathrm{g} / \mathrm{ml}$ resulted in even lower values than observed in cells without VEGF stimulation. The most likely explanation is that the peptide inhibits the stimulation of the cells by the growth factors (VEGF) present in the media. In accordance with the WST-1 analysis, the cells that are present in the wells treated with $100 \mu \mathrm{g} / \mathrm{ml}$ of ST100,038 show signs of apoptosis (cell death) and are in lower numbers than those present in wells without VEGF stimulation. We also tested whether the anti-proliferative activity of ST100,038 was specific for endothelial cells. Treatment of HT1080 fibrosarcoma cells with ST100,038 up to $80 \mu \mathrm{M}$ did not inhibit HT1080 survival (data not shown).

Characterization of anti-angiogenic activity of D-amino acid peptide derivative. The L-amino acid ST100,038 peptide has a very short half-life in serum. In $10 \%$ serum, $50 \%$ of the peptide was degraded in $4 \mathrm{~h}, 65 \%$ by $6 \mathrm{~h}$ and none remained at $18 \mathrm{~h}$ (data not shown). Considering the relatively limited stability of ST100,038 in serum, ST100,045 and ST100,059 peptides were synthesized using D-amino acids, as D-amino acid containing peptides are more stable in serum. These were tested for their serum stability and did not degrade under any of the tested conditions. ST100,045 has the same sequence of ST100,038 while ST100,059 is the ST100,038 retro-inverse peptide. The anti-angiogenic activity of ST100,045 on adherent BRE cells was minimal and substantially lower than ST100,038 as shown in Fig. 2A. In contrast to ST100,045, ST100,059 replicates the ability of ST100,038 to inhibit VEGF stimulation of endothelial cells when the peptides were added to the wells after the cells had adhered overnight (adherent cells) as shown in Fig. 2B.

We then tested whether the ability of these peptides to inhibit VEGF stimulation in vitro translated into anti-angiogenic 
A

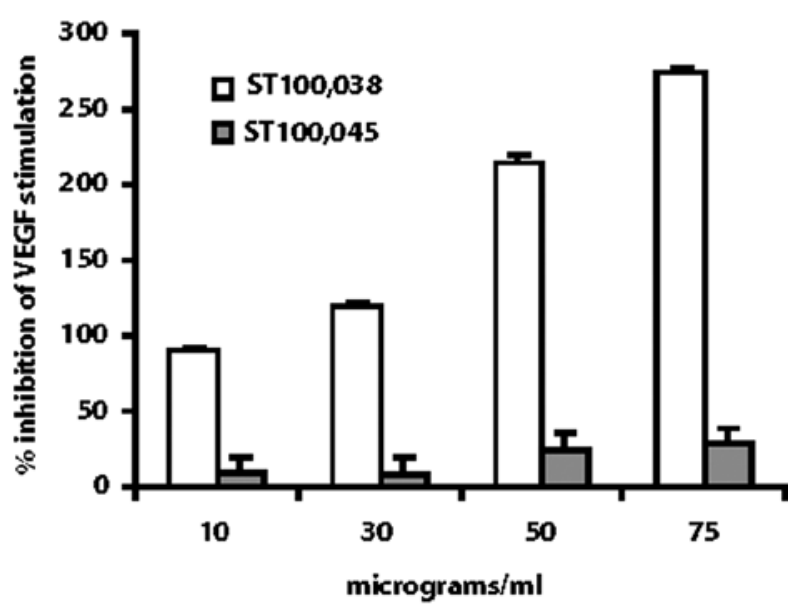

B

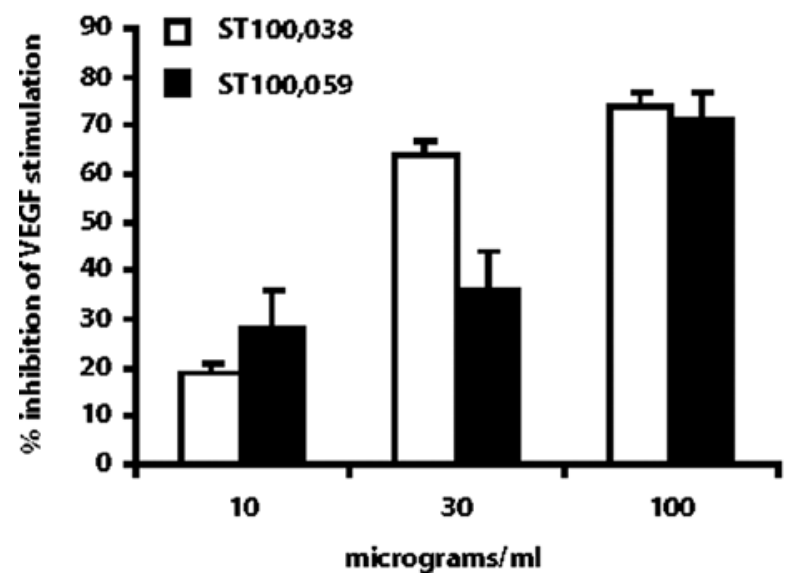

Figure 2. Effect of synthetic peptides on VEGF stimulation in HUVEC cells. (A), BRE cell cultures were grown in the presence of VEGF and were supplemented daily with various concentrations of peptides. Cells were measured WST1 after 5 days. Data are means of proliferation inhibition percentages for triplicate samples. (B), HUVEC cell cultures were grown in the presence of VEGF and were supplemented daily with various concentrations of peptides. Cells were measured WST1 after 5 days. Results are the mean \pm SEM of two separate experiments.

activity in vivo using a modified version of the Matrigel plug assay. This model analyzes VEGF-induced angiogenesis as it occurs in angioreactors filled with Matrigel and implanted in wild-type FVB/N mice and uses the TSP616 peptide as a positive control for inhibition $(12,17)$.

An initial experiment showed inhibition of VEGF-mediated angiogenesis, with ST100,038 being more active than ST100,045 (data not shown). A second experiment, summarized in Fig. 3A, showed that the ST100,038 and ST100,059 peptides clearly inhibited VEGF-mediated angiogenesis, with ST100,059 $(\mathrm{P}<0.01$ compared to VEGF) being more active than ST100,038 ( $\mathrm{P}<0.05$ compared to VEGF) similar to the unstimulated PBS controls and the TSP616 peptide ( $\mathrm{P}<0.01$ compared to VEGF). These results reflect that seen in vitro using BRE cells and confirms that of the two D-amino acid derivatives of ST100,038, the retro-inverse peptide ST100,059 is the more active.

Effect of ST100,059 on VEGF-induced intracellular signaling molecules. To further characterize its anti-angiogenic properties, we tested whether ST100,059 can inhibit VEGF-induced intracellular signaling. VEGF stimulation of the KDR receptor in endothelial cells results in the phosphorylation of MAPK that can be revealed with antibodies specific for phosphorylated MAPK. As shown in Fig. 3B, ST100,059 blocks VEGF-induced MAPK phosphorylation in a dose responsive fashion. The phosphorylation level of MAPK was calculated by normalizing the signal of phosphorylated form to total MAPK. This confirms that ST100,059 is blocking VEGF binding to KDR and the subsequent signal transduction pathway.

Effect of ST100,059 on VEGF-induced gene expression. In another test of ST100,059 activity, we determined whether ST100,059 could inhibit the expression of genes induced by VEGF in HUVEC cells. VEGF stimulation of the KDR receptor in endothelial cells results in substantial changes in gene expression that has been previously characterized. Gene expression levels obtained from unstimulated control, VEGFstimulated and VEGF plus ST100,059-treated HUVEC cells were compared to identify those genes that are either up-regulated or down-regulated by VEGF compared to control and whose levels were then brought back to levels similar to control by treatment with ST100,059.

Fig. 3C and D display a graphical representation of the results. These results show that ST100,059 is able to inhibit VEGF-induced gene expression changes for many genes previously described in the literature. The gene Down syndrome critical region gene 1 is used as an example of a VEGF upregulated gene. Of interest are those genes described in Yang et al which are specifically up-regulated by the KDR selective mutant of VEGF, considering that ST100,059 only blocks VEGF binding to KDR and not FLT-1, the other receptor (18). Of those genes, several are also up-regulated in our experiment and then completely inhibited by ST100,059. For example, hydroxysteroid (17- $\beta$ ) dehydrogenase 7 and stanniocalcin 1 is up-regulated 2.4 times and completely inhibited by ST100,059. Insulin-like growth factor binding protein 5 is up-regulated 4.5 times, $\gamma$ synuclein up-regulated 2 times and completely inhibited by ST100,059. The ets 2 gene is up-regulated 2.5 times and completely inhibited by ST100,059.

Effect of ST100,059 on B16-F1 melanoma tumors growth in vivo. Administration of ST100,059 significantly inhibited subcutaneous tumor growth, with increased inhibition of growth correlating with increasing amounts of ST100,059 (Fig. 4). When amounts of ST100,059 as low as $20 \mathrm{mg} / \mathrm{kg} /$ day were administered to tumor-bearing mice, growth of subcutaneous tumors was significantly inhibited. All administered levels of ST100,059 (20, 40 and $100 \mathrm{mg} / \mathrm{kg} /$ day) suppressed s.c. B16-F1 melanoma growth compared to untreated control groups throughout the period of these studies. As seen in Fig. 4, treatment with $100 \mathrm{mg} / \mathrm{kg}$ daily of ST100,059 resulted in similar levels of inhibition of tumor growth as seen with the clinicallyactive dose of doxorubicin.

Effect of ST100,059 on B16-F1 melanoma lung metastases. In our lung metastasis model, treatment with ST100,059 $(100 \mathrm{mg} / \mathrm{kg})$ daily or every other day over a period of 14 days significantly reduced the number of B16 melanoma lung metastases compared to vehicle treated controls (Fig. 5). Regular 
A
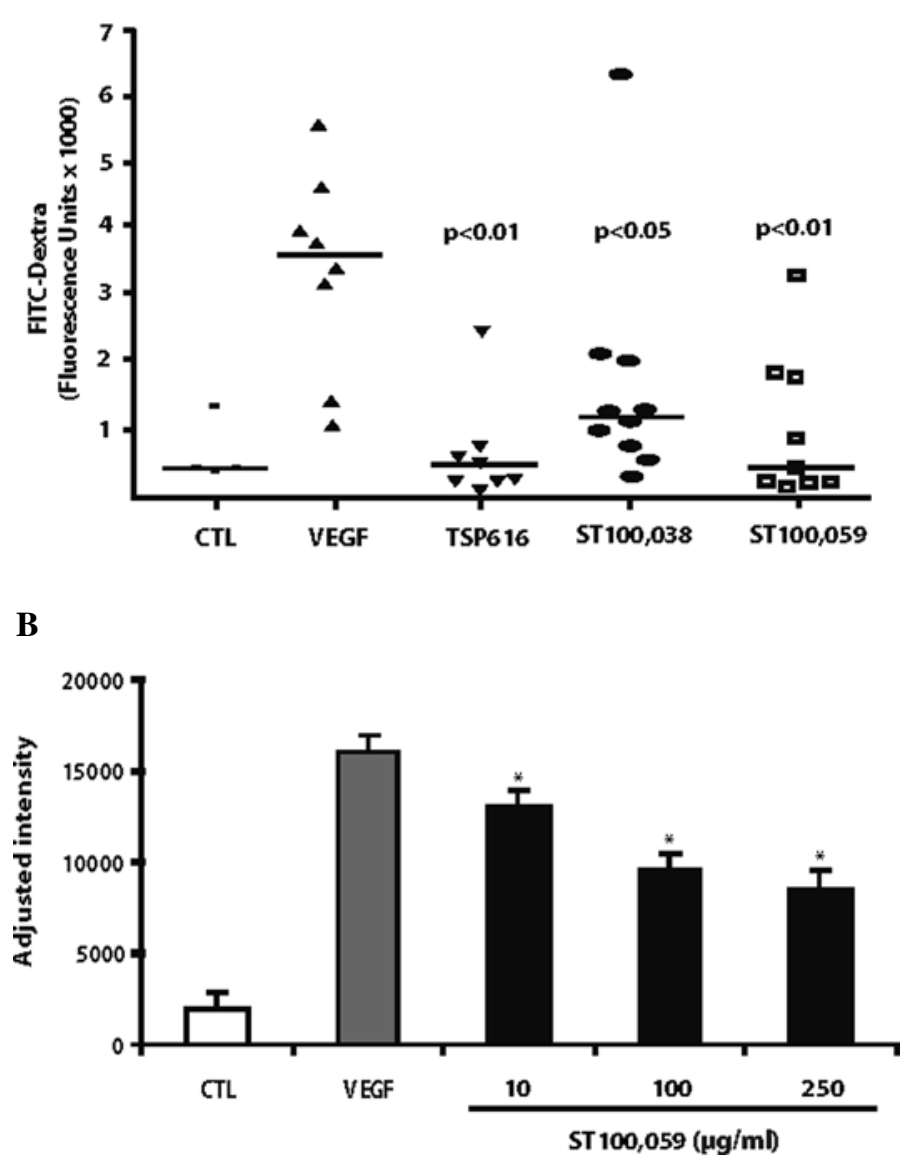

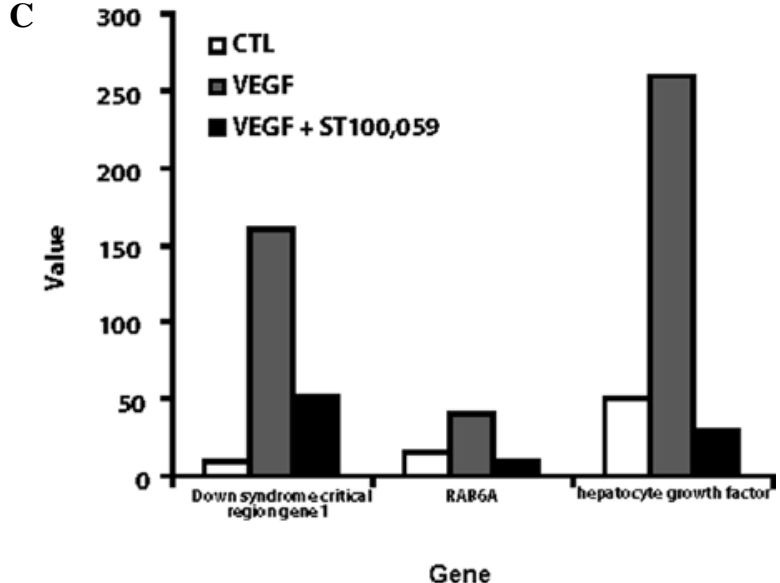

D

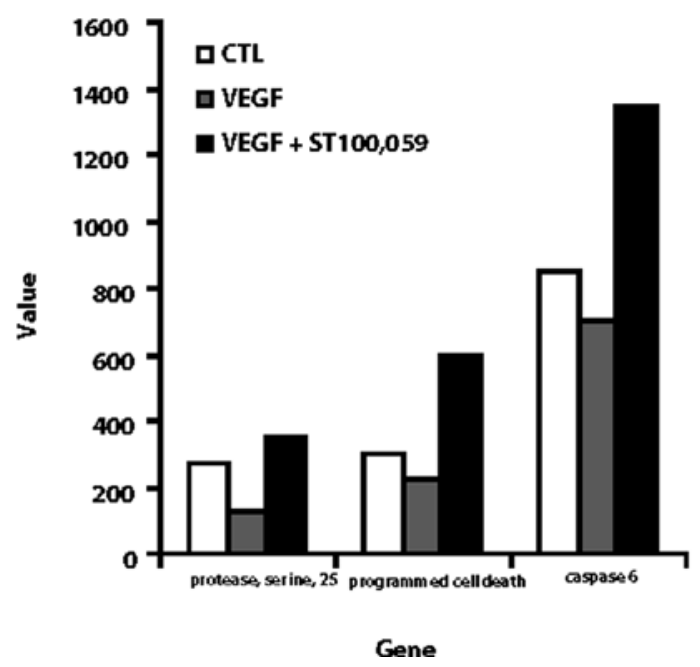

Figure 3. Effect of ST100,059 on VEGF-stimulated angiogenesis, intracellular signaling and gene expression. (A), The neovascularization of Matrigel plugs containing PBS (unstimulated), VEGF alone or in combination with TSP616, ST100,038 and ST100,059, was assessed as described in Materials and methods. Angiogenic score means and standard errors measured for eight implant groups. (B), HUVEC cells were starved overnight and then stimulated with 25 ng/ml of human VEGF165 in the presence or absence of increasing concentrations of ST100,059 peptide. The level of phosphorylation of MAPK was analyzed by Western blot analysis. (C and D), Total RNA was obtained from HUVEC cells, either starved or stimulated with $25 \mathrm{ng} / \mathrm{ml}$ of human VEGF165 in the presence or absence of ST100,059 peptide. The RNA was then hybridized on Affymetrix Human U133 Plus 2.0 arrays. The image represents those VEGF up-regulated genes (C) or down-regulated genes (D) whose change is inhibited by ST100,059 treatment.

determination of animal weight and gross examination of all groups of animals showed no obvious weight loss or any other manifestation of toxicity or pathology in these experimental animals. No significant reduction in metastatic lung tumors was noted in animals treated for only 7 days with ST100,059. Taken together, these results have shown that the extended administration of the anti-angiogenic ST100,059 peptide is probably necessary for significant efficacy against metastatic B16-F1 lung metastases.

Effect of ST100,059 on anti-angiogenic pathways in vivo. As ST100,059 is hypothesized to limit VEGF mediated angiogenesis in vivo by blocking VEGF binding to its receptor KDR, we designed studies to show that this was the mechanism underlying ST100,059 anti-tumor activity in vivo. We analyzed changes in the level of activation of the KDR signaling pathway in the tumors after ST100,059 treatment using two downstream targets, AKT and GSK3 $\beta$. The level of phosphorylation of AKT and GSK $3 \beta$ was determined by Western blot analysis of protein extracts from treated and untreated tumors. As shown in Fig. 6, these experiments show that in the ST100,059 treated tumors the phosphorylation level of these mediators of the KDR signaling pathway and major survival effectors for endothelial cells are strongly reduced. These in vitro and in vivo studies demonstrate that ST100, 059 indeed acts as an anti-angiogenic agent.

\section{Discussion}

The screening of peptide-displayed libraries is a powerful technique for identifying peptides with drug like properties (19). Since each peptide is physically linked to a genetic particle, clones specifically binding a target molecule can be selected by in vitro 'biopanning'. New agonists and antagonists for cell membrane receptors have been identified successfully using this process (20-23). Sopherion Therapeutics has developed a new peptide display technology that makes use of minicells, small sub cellular vesicles produced by bacteria undergoing an aberrant cell division process (24). The most striking difference with phages is that the minicells are terminal, 


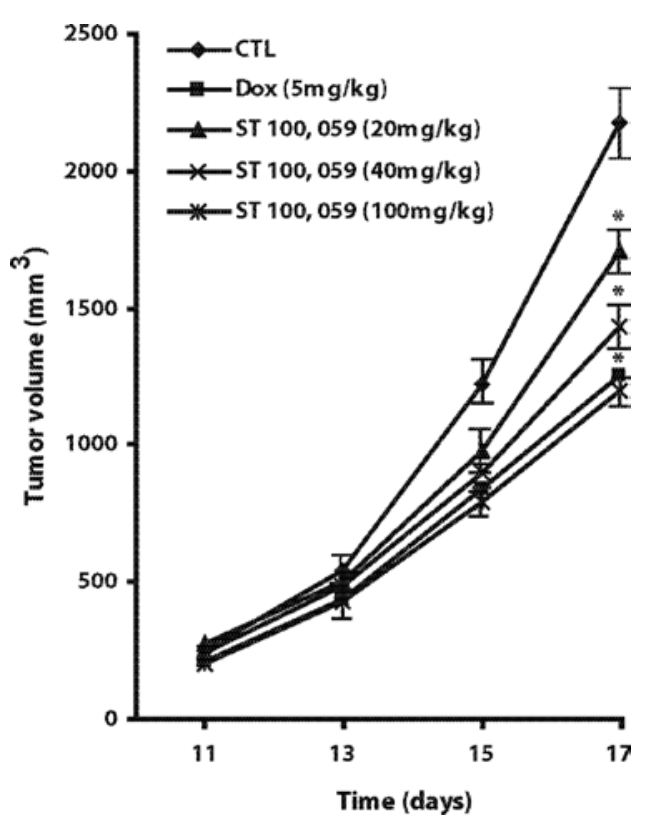

Figure 4. Effect of ST100,059 on B16-F1 melanoma tumor growth in vivo. Female C57BL/6 mice were inoculated with $5 \times 10^{5} \mathrm{~B} 16-\mathrm{F} 1$ cells in to right flank via s.c. route. Animals were treated with doxorubicin $(5 \mathrm{mg} / \mathrm{kg}), \mathrm{ST} 100,059$ $(20-100 \mathrm{mg} / \mathrm{kg} / \mathrm{day})$ or vehicle alone as control (CTL). Tumor volume of all animals was measured at timed intervals as described in Materials and methods. Results are the mean \pm SEM of ten animals in each group. Significant difference in tumor volume from control is shown by asterisks $(\mathrm{P}<0.05)$.

non-replicating entities hence a variety of limitations associated with maintaining viability during the production/display of the peptide and the screening process are removed. In addition, the expression of the library peptides on the minicell surface eliminates the steric hindrance problems inherent with the expression of peptides linked to viral coat proteins in phage display $(25,26)$.

We have demonstrated the ability of the new MPD technology to generate and identify peptides with therapeutic relevance. We decided to screen for peptide ligands to the human VEGF receptor KDR because of the medical relevance of this pathway in the context of pathological angiogenesis in regard to the treatment of cancer. VEGF is one of the most critical growth factors responsible for stimulating endothelial cell proliferation, migration, and new blood vessel formation. Among the peptide ligands identified, one appeared to contain 2 smaller binding subdomains, LPP and HSS that were previously identified in a phage display experiment in two different peptides. This supports our claim that MPD can identify peptides that cannot be recognized due to the constraints of phage display. In addition, the MPD peptide has a better activity, as would be expected if the interaction surface with KDR is wider. This MPD derived synthetic peptide and its D-amino acid derivative inhibits VEGF-dependent stimulation of the proliferation endothelial cells as well as suppresses VEGF-induced blood vessel formation in the Matrigel plug assays. This anti-angiogenic activity translates in the ability to inhibit tumor progression and lung metastasis in a B16 mouse melanoma model. This inhibition is achieved via an anti-angiogenic mechanism of action as demonstrated using molecular marker like CD31 immunostaining and the level of phosphorylation of downstream targets in the KDR signaling pathway (27).
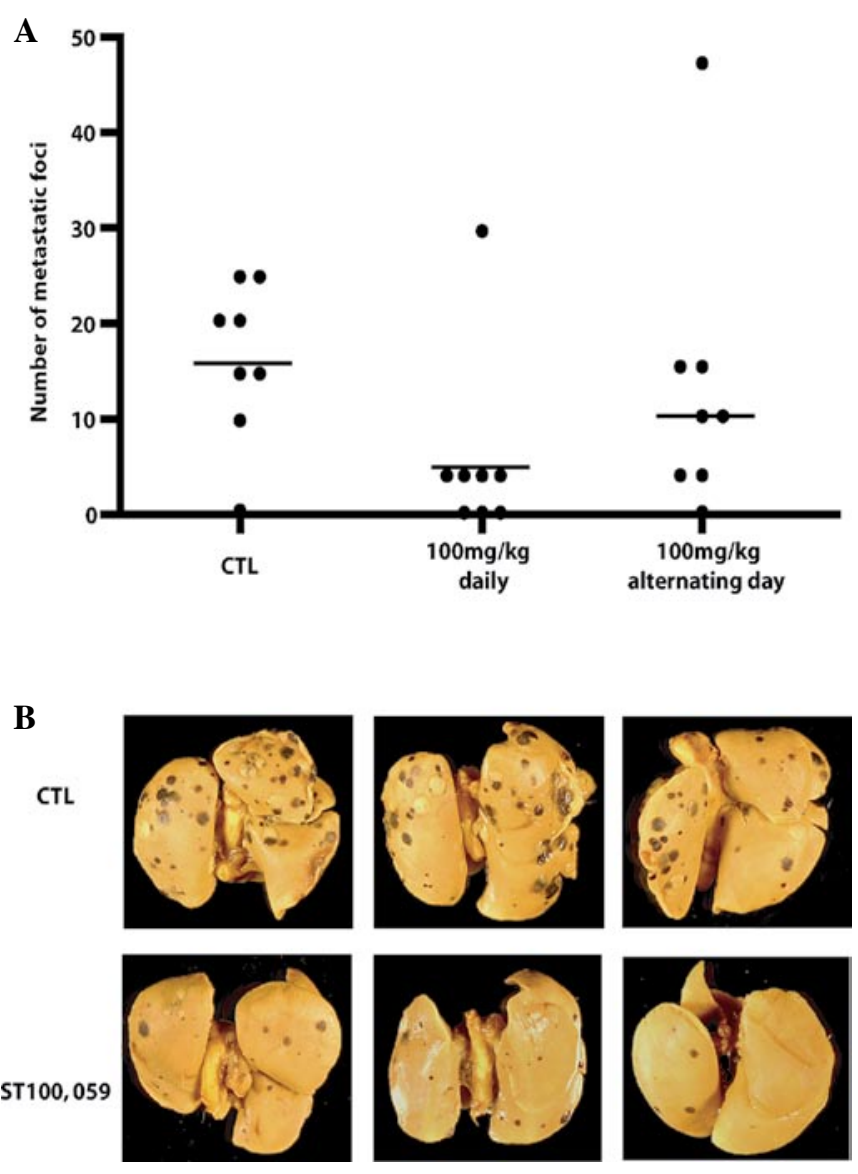

Figure 5. Effect of ST100,059 on B16-F1 lung metastasis in vivo. The ability of ST100,059 to block B16-F1 melanoma metastasis to the lungs was examined by injecting $1 \times 10^{5} \mathrm{~B} 16-\mathrm{F} 1$ cell into tail vein of female C57BL6 mice. Animals were treated with vehicle alone as control (CTL) or $100 \mathrm{mg} / \mathrm{kg}$ of ST100,059 daily or alternate days for 14 days and number of lung metastasis was determined as described in Materials and methods (A). Photomicrographs of representative lungs from control and experimental animals are shown (B). Results are the mean \pm SEM of eight animals in each group.

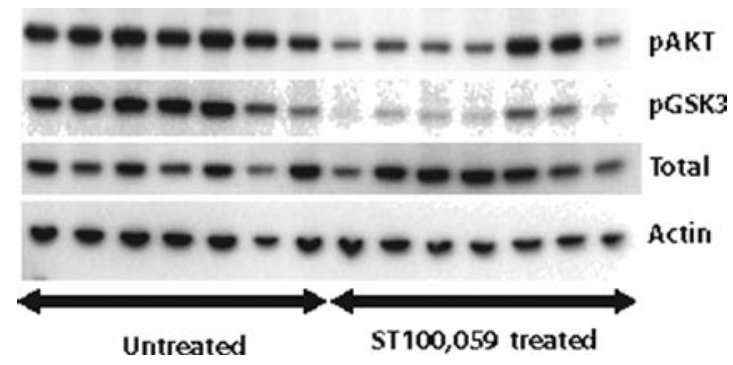

Figure 6. Effect of ST100,059 on B16-F1 melanoma tumors intracellular signaling pathways. Representative B16 melanoma tumors from animals treated with vehicle alone as control (CTL) or $100 \mathrm{mg} / \mathrm{kg} / \mathrm{day}$ of ST100,059 were removed and subjected to Western blot analysis to determine the change in the expression of intracellular signaling pathways as described in Materials and methods.

Introduction of $\mathrm{D}$-amino acids into bioactive peptide sequences greatly improves their resistance to proteolytic degradation, but it does not always maintain bioactivity (28). The simplest modification is the retro-inverso approach, where all amino acid are replaced by of D-amino acid and the sequence is inverted. This new peptide should maintain the stereochemical configuration of the original peptide, as opposed to the all- 
D amino acid peptide which would be a mirror image of the original. The retro-inverso peptides have shown a higher propensity to retain the biological activity (29). Similarly, only the retro-inverso of 038,059 , retains the biological activity while gaining resistance to proteolytic degradation.

Disruption of VEGF signaling has also been accomplished by using monoclonal antibodies to VEGF (9). One drawback of this approach is the cost of generating of the antibody which results in a very expensive therapy. We believe that therapy with small peptides will have substantial cost benefit. The major class of anti-angiogenic molecules in clinical development is small molecule inhibitors of the kinase activity of RTK receptor like KDR (30). Most of these kinase inhibitors are ATP competitors because they have been identified by bio-chemical screens using the active form of the kinase domain of the receptor. In general none of these molecules can achieve the same specificity of a peptide targeted to block the protein-protein interaction between a ligand and its receptor. Due to the structural similarity of the catalytic domain of kinases in general, they usually lack a high level of specificity and therefore they inhibit several RTK receptors.

In summary, our results demonstrate that the ST100,059 peptide is an effective antagonist of VEGF, functions as an inhibitor of angiogenesis in vitro and in vivo and has shown anti-tumor activity against both primary tumors and metastases. This suggests that this peptide as a KDR antagonist might have potential application for the treatment of a variety of cancers. The small size of this peptide also offers the possibility of generating structurally similar molecules via standard organic synthesis and or modeling; this could therefore represent a novel approach to targeted drug design.

\section{Acknowledgments}

This work was supported by the Canadian Institutes of Health Research (CIHR) grant MOP 10630 to S.A.R. We gratefully acknowledge our colleagues Lisa Lagasse and James Matson for their help and advice. Pieter Koolwijk and Erik Kaijzel at TNO Pharma performed the in vivo angioreactor model.

\section{References}

1. Cliff WJ, Martin JD and Michael CA: Use of ear chamber with uterine muscle transplant to differentiate myometrial and vascular activity. Nature 199: 399-400, 1963.

2. Schoefl GI: Studies on inflammation. III. Growing capillaries: their structure and permeability. Virchows Arch Pathol Anat Physiol Klin Med 337: 97-141, 1963.

3. Ausprunk DH and Folkman J: Migration and proliferation of endothelial cells in preformed and newly formed blood vessels during tumor angiogenesis. Microvasc Res 14: 53-65, 1977.

4. Distler JH, Hirth A, Kurowska-Stolarska M, Gay RE, Gay S and Distler O: Angiogenic and angiostatic factors in the molecular control of angiogenesis. Q J Nucl Med 47: 149-161, 2003.

5. Hendrix MJ, Seftor EA, Hess AR and Seftor RE: Vasculogenic mimicry and tumour-cell plasticity: lessons from melanoma. Nat Rev Cancer 3: 411-421, 2003.

6. Hida K, Hida Y, Amin DN, Flint AF, Panigrahy D, Morton CC and Klagsbrun M: Tumor-associated endothelial cells with cytogenetic abnormalities. Cancer Res 64: 8249-8255, 2004.

7. Ferrara N: Role of vascular endothelial growth factor in regulation of physiological angiogenesis. Am J Physiol Cell Physiol 280: C1358-C1366, 2001.

8. Ahmed SI, Thomas AL and Steward WP: Vascular endothelial growth factor (VEGF) inhibition by small molecules. J Chemother 16 (Suppl 4): 59-63, 2004.
9. Ferrara N, Hillan KJ, Gerber HP and Novotny W: Discovery and development of bevacizumab, an anti-VEGF antibody for treating cancer. Nat Rev Drug Discov 3: 391-400, 2004.

10. Zhu Z and Witte L: Inhibition of tumor growth and metastasis by targeting tumor-associated angiogenesis with antagonists to the receptors of vascular endothelial growth factor. Invest New Drugs 17: 195-212, 1999.

11. Binetruy-Tournaire R, Demangel C, Malavaud B, Vassy R, Rouyre S, Kraemer M, Plouet J, Derbin C, Perret G and Mazie JC: Identification of a peptide blocking vascular endothelial growth factor (VEGF)-mediated angiogenesis. EMBO J 19: 1525-1533, 2000.

12. Guedez L, Rivera AM, Salloum R, Miller ML, Diegmueller JJ, Bungay PM and Stetler-Stevenson WG: Quantitative assessment of angiogenic responses by the directed in vivo angiogenesis assay. Am J Pathol 162: 1431-1439, 2003.

13. Pasco S, Ramont L, Venteo L, Maquart FX and Monboisse JC: In vivo overexpression of tumstatin domains by tumor cells inhibits their invasive properties in a mouse melanoma model. Exp Cell Res 301: 251-265, 2004.

14. Qiu H, Orr FW, Jensen D, Wang HH, McIntosh AR, Hasinoff BB, Nance DM, Pylypas S, Qi K, Song C, Muschel RJ and AlMehdi AB: Arrest of B16 melanoma cells in the mouse pulmonary microcirculation induces endothelial nitric oxide synthasedependent nitric oxide release that is cytotoxic to the tumor cells. Am J Pathol 162: 403-412, 2003.

15. Chen G, Shukeir N, Potti A, Sircar K, Aprikian A, Goltzman D and Rabbani SA: Up-regulation of Wnt-1 and beta-catenin production in patients with advanced metastatic prostate carcinoma: potential pathogenetic and prognostic implications. Cancer 101: 1345-1356, 2004.

16. Lu D, Shen J, Vil MD, Zhang H, Jimenez X, Bohlen P, Witte L and Zhu Z: Tailoring in vitro selection for a picomolar affinity human antibody directed against vascular endothelial growth factor receptor 2 for enhanced neutralizing activity. J Biol Chem 278: 43496-43507, 2003.

17. Iruela-Arispe ML, Lombardo M, Krutzsch HC, Lawler J and Roberts DD: Inhibition of angiogenesis by thrombospondin-1 is mediated by 2 independent regions within the type 1 repeats. Circulation 100: 1423-1431, 1999.

18. Yang S, Toy K, Ingle G, Zlot C, Williams PM, Fuh G, Li B, De Vos A and Gerritsen ME: Vascular endothelial growth factorinduced genes in human umbilical vein endothelial cells: relative roles of KDR and Flt-1 receptors. Arterioscler Thromb Vasc Biol 22: 1797-1803, 2002.

19. Landon LA, Zou J and Deutscher SL: Is phage display technology on target for developing peptide-based cancer drugs? Curr Drug Discov Technol 1: 113-132, 2004.

20. Sato A and Sone S: A peptide mimetic of human interferon (IFN)-beta. Biochem J 371: 603-608, 2003.

21. Bonetto S, Carlavan I and Baty D: Isolation and characterization of antagonist and agonist peptides to the human melanocortin 1 receptor. Peptides 26: 2302-2313, 2005.

22. Koolpe M, Burgess R, Dail M and Pasquale EB: EphB receptorbinding peptides identified by phage display enable design of an antagonist with ephrin-like affinity. J Biol Chem 280: 17301-17311, 2005.

23. An P, Lei H, Zhang J, Song S, He L, Jin G, Liu X, Wu J, Meng L, Liu M and Shou C: Suppression of tumor growth and metastasis by a VEGFR-1 antagonizing peptide identified from a phage display library. Int J Cancer 111: 165-173, 2004.

24. Khachatourians GG, Clark DJ, Adler HI and Hardigree AA: Cell growth and division in Escherichia coli: a common genetic control involved in cell division and minicell formation. J Bacteriol 116: 226-229, 1973.

25. Makowski L: Structural constraints on the display of foreign peptides on filamentous bacteriophages. Gene 128: 5-11, 1993.

26. Wilson DR and Finlay BB: Phage display: applications, innovations, and issues in phage and host biology. Can J Microbiol 44: 313-329, 1998.

27. Zachary I: VEGF signalling: integration and multi-tasking in endothelial cell biology. Biochem Soc Trans 31: 1171-1177, 2003.

28. Fischer PM: The design, synthesis and application of stereochemical and directional peptide isomers: a critical review. Curr Protein Pept Sci 4: 339-356, 2003.

29. Chorev M: The partial retro-inverso modification: a road traveled together. Biopolymers 80: 67-84, 2005.

30. Damiano V, Melisi D, Bianco C, Raben D, Caputo R, Fontanini G, Bianco R, Ryan A, Bianco AR, De Placido S, Ciardiello F and Tortora G: Cooperative antitumor effect of multitargeted kinase inhibitor ZD6474 and ionizing radiation in glioblastoma. Clin Cancer Res 11: 5639-5644, 2005. 